ORIGINAL RESEARCH

\title{
Prevalence of Third Molar Agenesis in Patients-A Panoramic Retrospective Study
}

\author{
Vivek Padmanabhan ${ }^{1}$,, Omar Khaled AR Abo Mostafa ${ }^{2}$, Lama M Kamel Rahhal ${ }^{3}$
}

\begin{abstract}
Background/purpose: The most common developmental dental problem is that of agenesis. It is seen to affect around about $25 \%$ of the population. The aim of this study is to determine the prevalence of agenesis of third molars in patients visiting a dental college in the UAE. Materials and methods: Orthopantomograms (OPGs) of 945 dental patients aged 6-30 years were evaluated for bilateral agenesis or congenitally missing teeth. Bilateral agenesis was considered and unilateral missing teeth were excluded from the study. Descriptive statistics were used to describe the percentages and frequencies were calculated using Chi-square test and the level of significance was considered if the $p$ value was $<0.05$. Results: Eighty-five of the 945 OPGs showed bilateral agenesis. The prevalence of bilateral agenesis or congenitally missing third molars within the selected 85 OPGs was at $31.76 \%$.
\end{abstract}

Conclusions: The prevalence rate of bilateral agenesis or congenitally missing permanent third molars is high at $31.76 \%$.

Keywords: Agenesis, Orthopantomograms, Third molars.

Journal of Contemporary Dentistry (2020): 10.5005/jp-journals-10031-1301

\section{INTRODUCTION}

Teeth which have not erupted at their usual times of eruption into the oral cavity are known by the term "agenesis." It is one of the most common dental anomalies found in human beings. Whenever there is a complete absence of teeth, it is referred to as "anodontia." When the number of missing teeth is six or more, then it is referred to as "oligodontia."1,2 Hypodontia is a term used to refer to a condition when there are less than six teeth found missing. ${ }^{2}$

The tooth with the highest prevalence rate of agenesis is usually the third molar and is also referred to as "vestigial" at times.,

Ever since the evolution of human beings has occurred, there have been dramatic cultural and biological changes that have taken place in the human race, and these changes have also been reflected in the diet of human beings. ${ }^{3}$ The diet of humans is now more refined when compared to our ancestors, and this has also been suggested as a reason for decreasing dependency on the third molars and also reduced jaw size, resulting in an increasing prevalence of agenesis of third molars as evolution has happened. ${ }^{3,4}$

One of the characteristic features of third molars is the variability that it exhibits in its formation and odontogenesis and by its varying rates of being present or absent within the oral cavity. ${ }^{5}$ The different stages of odontogenesis of third molars inclusive of development, calcification, and eruption show a huge variation. At times, the development of the third molars can be initiated at the age of 5 years or maybe toward the early 7 th year of life. The calcification of the third molars can begin as early as at the age of 7 years or can be delayed until the age of $16-17$ years in some individuals. ${ }^{6}$ The etiology of agenesis could be attributed to environmental factors, genetic polymorphisms, systemic diseases, dietary habits, and masticatory function. ${ }^{7,8}$ The genetic etiology is usually attributed to the mutation of some genes (PAX9 and MSX1) in addition to some other etiological reasons in the prenatal and postnatal periods. ${ }^{9}$ Studies which compared the gender predilection suggested that the prevalence of agenesis was more in women than men. ${ }^{10}$ Racial comparisons revealed that there is a lesser rate of prevalence in the black race when compared to the whites and
${ }^{1}$ Department of Pediatric and Preventive Dentistry, RAK College of Dental Sciences, RAK Medical and Health Sciences University, Ras Al Khaimah, United Arab Emirates

${ }^{2,3}$ RAK College of Dental Sciences, RAK Medical and Health Sciences University, Ras Al Khaimah, United Arab Emirates

Corresponding Author: Vivek Padmanabhan, Department of Pediatric and Preventive Dentistry, RAK College of Dental Sciences, RAK Medical and Health Sciences University, Ras Al Khaimah, United Arab Emirates, Phone: +971 527400018, e-mail: vivek.padmanabhan@rakmhsu.ac.ae How to cite this article: Padmanabhan V, Mostafa OKARA, Rahhal LMK. Prevalence of Third Molar Agenesis in Patients-A Panoramic Retrospective Study. J Contemp Dent 2020;10(1):9-12.

Source of support: Nil

Conflict of interest: None

that Asians showed an increased prevalence of agenesis. ${ }^{10}$ There have been studies which have shown a prevalence of $12.7 \%$ in the British population. ${ }^{11}$ Another study among the Chilean population showed a prevalence rate of $24.75 \%{ }^{12}$ and a high prevalence rate of $41 \%$ was seen in the Korean population. ${ }^{13}$ These variations can be attributed to factors like sample size, the population included, race investigated, and also not to forget genetic mutations which can result in agenesis as a result of evolution also.

The present study is designed to understand the prevalence of bilateral agenesis of the third molars among a population of patients visiting a dental college in the UAE. The study is also intended to understand the gender and arch predilection of bilateral agenesis of the third molars.

\section{Materials and Methods}

This was a retrospective, observational study conducted after approval from the Research and Ethics Committee at RAK College of Dental Sciences (RAKCODS), RAK Medical and Health Sciences 
University (RAKMHSU), RAK, UAE. The objective of this study is to understand the prevalence of bilateral agenesis of the third molars. The study is also intended to evaluate the gender and arch predilection of bilateral agenesis of the third molars. The age-group of patients for whom the orthopantomograms (OPGs) were selected was between 6 years and 30 years of age. Orthopantomograms which showed bilateral agenesis of the third molars were included. Since a clinical examination of these patients was not possible, only those OPGs which showed bilateral absence were considered to be true agenesis and were included in the present study.

Nine hundred forty-five OPGs at the oral radiology center of the university were used out of the total 18,500 OPGs available. These 945 OPGs were selected based upon the age-group, clarity of the OPG, presence of details in the OPG, and E-file of patients on the hospital information management system (HIMS). Patients with syndromes or other special needs patients as per the E-file records on HIMS were excluded from the study and also edentulous patients were not included. Also, patients who had periapical X-rays on their files which showed possible extraction of these (third molars, mandibular second premolars, and maxillary lateral incisors) teeth were excluded from the study. Once these 945 OPGs were selected, then a second level of inclusion and exclusion criteria in terms of evaluating for bilateral agenesis of the third molars was used to understand true agenesis.

\section{Statistical Analysis}

Data observed in this study were described using descriptive statistical analysis. To evaluate the frequency of agenesis between sexes (males/females) and between the maxillary and mandibular arches where applicable Chi-square statistical test was applied, the level of significance was set at $p<0.05$.

\section{Results}

A total of 945 OPGs were initially included in the study of the 18,500 OPGs which were available for review in the dental radiology center of the university. These OPGs were initially evaluated based upon the criteria like age-group. Then, these 945 OPGs were categorized based upon the presence of bilateral agenesis.

Eighty-five OPGs of the 945 OPGs revealed bilateral agenesis of teeth; of the 85 OPGs which revealed bilateral agenesis, $31.76 \%$ showed bilateral agenesis or congenitally missing third molars. Hence, the prevalence of bilateral agenesis of the third molars or congenitally missing third molars is $31.76 \%$ (27 OPGs showed bilateral agenesis of the third molars) (Fig. 1). The 27 OPGs which showed bilateral agenesis comprised 15 males and 12 females.

The prevalence of bilateral agenesis or congenitally missing teeth was seen more in males (55.55\%) than females (44.44\%) (Table 1); within these 27 OPGs, the results were, however, not statistically significant $\left(X^{2}=0.84, p=0.30\right)$.

The prevalence of bilateral agenesis or congenitally missing teeth was more in the mandibular arch (51.85\%) than the maxillary arch (48.14\%) (Table 2); within these 27 OPGs, these results were also not statistically significant $\left(X^{2}=1.30, p=0.26\right)$.

\section{Discussion}

The most common dental anomaly in humans is tooth agenesis and this agenesis is at times associated with other anomalies, structural malformations, delayed eruption, crowding, and juxtaposition. ${ }^{6}$ Agenesis of teeth can affect both primary and permanent dentition.

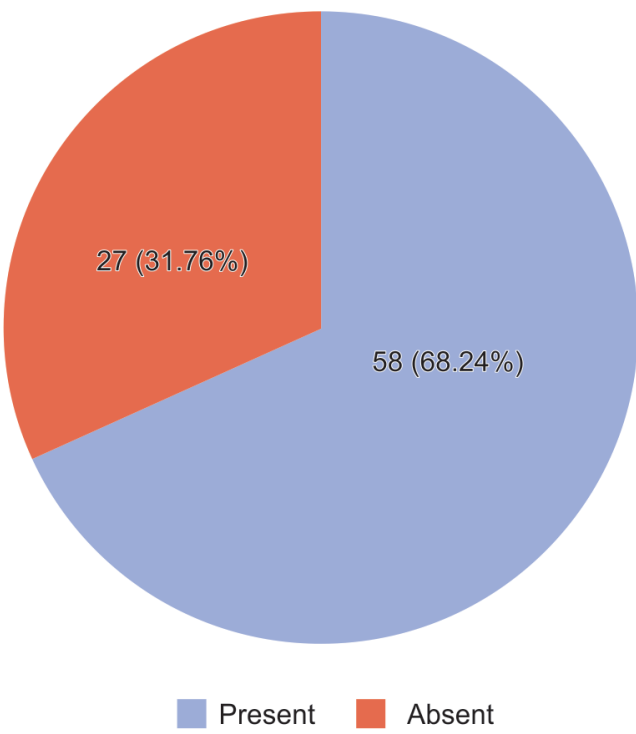

Fig. 1: Prevalence (\%) of bilateral agenesis of the third molar or congenitally absent third molars

Table 1: Prevalence of bilateral agenesis of third molars or congenitally missing third molars between males and females

\begin{tabular}{lllll}
\hline Total & Male & Female & $X^{2}$ (Chi-square) & Sig $p$ value \\
\hline 27 & 15 & 12 & 0.84 & 0.30 \\
$100 \%$ & $55.55 \%$ & $44.44 \%$ & & \\
\hline
\end{tabular}

$p>0.05$ not significant (ns); $p<0.05$ significant (s); $p<0.01$ highly significant (hs); $p<0.001$ very highly significant (vhs)

Table 2: Prevalence of bilateral agenesis of third molars or congenitally missing third molars between maxillary and mandibular arches

\begin{tabular}{lllll}
\hline Total & Maxillary arch & Mandibular arch & $X^{2}$ (Chi-square) & Sig $p$ value \\
\hline 27 & 13 & 14 & 1.30 & 0.26 \\
$100 \%$ & $48.14 \%$ & $51.85 \%$ & & \\
\hline
\end{tabular}

$p>0.05$ not significant (ns); $p<0.05$ significant (s); $p<0.01$ highly significant (hs); $p<0.001$ very highly significant (vhs)

These anomalies are genetic in origin and hereditary in nature most of the time. ${ }^{5}$ Nearly $25 \%$ of the population is affected by tooth agenesis. ${ }^{7}$

The present study was designed to determine the prevalence of bilateral agenesis or congenitally missing third molars among all nonsyndromic patients who had visited RAKCODS Clinics. In the present study, a tooth was diagnosed as congenitally missing or having agenesis when there was no mineralization of its crown on the OPG, and no evidence of its extraction on both the OPG and also on the patient's E-file on HIMS.

It is understood that the prevalence of third molar agenesis can vary based upon race and other evolutionary changes like diet and nutrition. ${ }^{8}$ Genetics has also been found to be a contributory factor in the changes of incidence of third molar agenesis. ${ }^{8,14}$ There have been studies which have reported a difference in incidence rates found worldwide (Fig. 2). ${ }^{15,16}$

\section{Bilateral Agenesis or Congenital Absence of Third Molars}

In the present study, it was seen that the prevalence rate of bilateral agenesis or congenitally missing third molars is at $31.76 \%$. The high prevalence of third molar agenesis seen in the present study can 

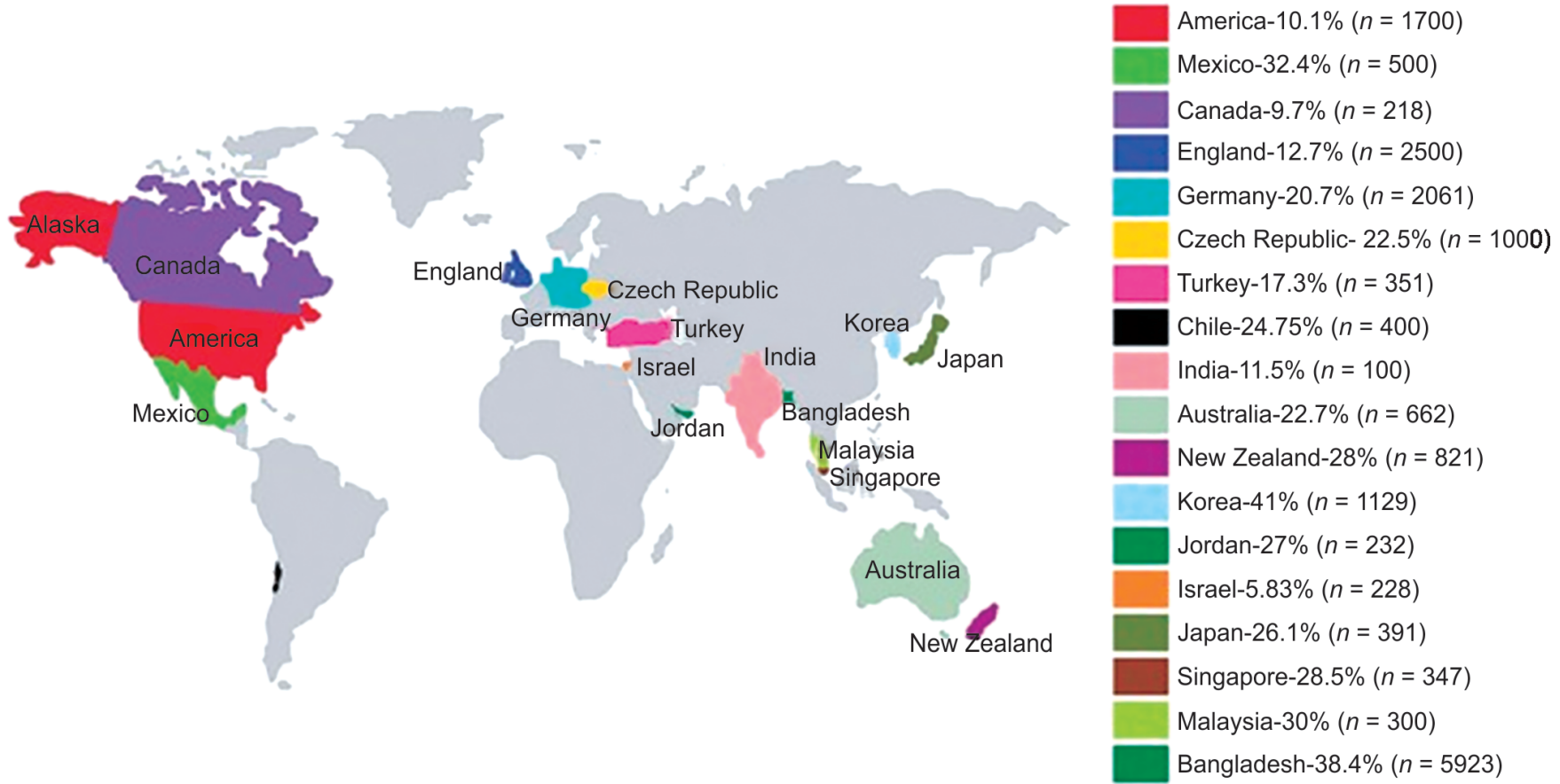

Fig. 2: Prevalence rate of third molar agenesis seen in different studies worldwide ${ }^{14,16}$

be due to the reduced number of OPGs which were included in the present study; however, yet the percentage remains high. There are studies which have reported high percentages, ranging from 24.75 to $41 \% .^{16}$ Genetics seems to play an important role in these high prevalence rates usually found in studies. Bone morphogenetic protein-4, produced early in dental epithelial development, regulates mesenchymal tooth-specific gene expression, including that of the MSX1 gene. ${ }^{17,18}$ A missense mutation in the MSX1 gene at chromosome 4p16.1 appears to be responsible for the third molar agenesis. ${ }^{18}$ The synergistic effects of both the genetic influence and the corresponding growth factors are possibly associated with agenesis of the third molars. ${ }^{17,18}$ Further, it has been suggested that third molar agenesis is also associated with decreased maxillary and mandibular jaw size as a result of continuous human evolution. $^{18}$

\section{Gender Predilection}

The prevalence of bilateral agenesis or congenitally missing teeth was seen more in males (55.55\%) than females (44.44\%) (Table 1). The results of the present study are similar to those of studies done in Iran, Australia, and Finland, which also showed higher incidence rates in males when compared to females. ${ }^{8.19,20}$ However, there are other studies which usually have shown increased incidence rates in females compared to males. ${ }^{10,21}$ It has been shown in studies that the prevalence of hypodontia is usually higher in females. ${ }^{10}$ Though there are not many plausible reasons that have been found in the literature regarding this finding of increased prevalence in either gender, there was a suggestion in one of the studies by Graber where it is suggested that genetics plays an important role in intersexual differences, though not much of an explanation was given. ${ }^{22}$

\section{Arch Predilection}

The prevalence of bilateral agenesis or congenitally missing third molars was more in the mandibular arch (51.85\%) than the maxillary arch (48.14\%) (Table 2). A similar prevalence rate was found in a Swedish study done by Backman et al. ${ }^{23}$ However, there are other studies which have shown a higher rate of prevalence of congenital absence of teeth in the maxillary arch when compared to the mandibular arch., ${ }^{42}$ The reason provided for a higher prevalence in the maxilla was suggested to be due to the presence of different innervations. ${ }^{16}$ In the present study, though there was a higher prevalence in the mandibular arch, it was not statistically significant and we have no plausible reasons to suggest this as a cause for this finding.

At the end of this study, the authors agreed that there should be more studies done to understand the influence genetics can have on the agenesis of teeth and what evolution of human beings means to the agenesis of the third molars. The authors believed that if there is more evolution of the human race, then there can be a time when the third molars may cease to exist.

\section{Conclusion}

In the present study, we found that

- The prevalence rate of bilateral agenesis or congenitally missing third molars is high.

- The bilateral agenesis or congenitally missing third molars was found to have a high prevalence in males when compared to females.

- The bilateral agenesis or congenitally missing third molars was found to be more common in the mandible than the maxilla.

\section{OrCID}

Vivek Padmanabhan @ https://orcid.org/0000-0002-5331-0657

\section{References}

1. Kokich VO Jr, Kinzer GA. Managing congenitally missing lateral incisors Part II: tooth-supported restorations. J Esthet Restor Dent 2005;17(2):76-84. DOI: 10.1111/j.1708-8240.2005.tb00089.x. 
2. Abu-Hussein M, Watted N, Azzaldeen A, et al. Prevalence of missing lateral incisor agenesis in an orthodontic Arabs population in Israel (Arab48). Int J Public Health Res 2015;3(3):101-107. DOI: 10.15761/ ohc.1000106.

3. Pitekova L, Satko I. Controversy of third molars. Bratisl Lek Listy 2009;110(2):110-111. PMID: 19408843.

4. Kaur B, Sheikh S, Pallagatti S. Radiographic assessment of agenesis of third molars and para-radicular third molar radiolucencies in population of age group 18-25 years old - a radiographic survey. Arch Oral Res 2012;8(1):13-18.

5. Bindayel NA. The role of third molar in orthodontic treatment. Pak Oral Dent J 2011;31:374-378. DOI: 10.12669/pjms.342.14804.

6. Hentisz AY. Radiographic study of third molar agenesis in a sample from the American Midsouth [Master's thesis]. University of Tennessee; 2003.

7. Larmour C, Mossey PA, Thind BS, et al. Hypodontia - a retrospective review of prevalence and etiology. Part I. Quintessence Int 2005;36(4):263-270. PMID: 15835422.

8. Vahid-Dastjerdi E, Borzabadi-Farahani A, Mahdian M, et al. Nonsyndromic hypodontia in an Iranian orthodontic population. J Oral Sci 2010;52(3):455-461. DOI: 10.2334/josnusd.52.455.

9. De Coster PJ, Marks LA, Martens LC, et al. Dental agenesis: genetic and clinical perspectives. J Oral Pathol Med 2009;38(1):1-7. DOI: 10.1111/j.1600-0714.2008.00699.x.

10. Polder BJ, Van't Hof MA, Van der Linden FP, et al. A meta-analysis of the prevalence of dental agenesis of permanent teeth. Community Dent Oral Epidemiol 2004;32(3):217-226. DOI: 10.1111/j.1600-0528.2004.00158.x.

11. Shinn DL. Congenitally missing third molars in a British population. J Dent 1976;4(1): 42-44. DOI: 10.1016/0300-5712(76)90069-5.

12. Garcia-Hernandez F, Toro Yagui O, Vega Vidal M, et al. Third molar agenesis in young people between 14 and 20 years of age, Antofagasta, Chile. Int J Morphol 2008;26(4):825-832. DOI: 10.4067/ s0717-95022008000400008.
13. Lee SH, Lee JY, Park HK, et al. Development of third molars in Korean juveniles and adolescents. Forensic Sci Int 2009;188(1-3)107-111. PMID: 19410395. DOI: 10.1016/j.forsciint.2009.03.033.

14. Haralabakis $\mathrm{H}$. Observation on the time of eruption, congenital absence and impaction of the third molar teeth. Tans Eur Orthod Soc 1957;33:308-312.

15. Byahatti S, Ingafou MS. Prevalence of eruption status of third molars in Libyan students. Dent Res J (Isfahan) 2012;9(2):152-157. DOI: 10.4103/1735-3327.95228

16. Singh N, Chaudhari S, Chaudhari R, et al. A radiographic survey of agenesis of the third molar: a panoramic study. J Forensic Dent Sci 2017;9(3):130-134. DOI: 10.4103/jfo.jfds_59_16.

17. Nanda RS, Chawla TN. Status of third molar teeth. J Dent Assoc 1959;31(2):19-29.

18. Kapadia H, Mues G, D'Souza R. Genes affecting tooth morphogenesis. Orthod Craniofac Res 2007;10(3):105-113. DOI: 10.1111/j.16016343.2007.00395.x.

19. Lynham A. Panoramic, radiographic survey of hypodontia of Australian defense forces recruits. Austr Dent J 1989;35(1):19-22. DOI: 10.1111/j.1834-7819.1990.tb03021.x.

20. Mueroma $H$, Turtola $L$, Ylipaavalnielmi $P$, et al. Status of the third molars in the 20 to 21 year old Finish University population. J Am Coll Health 1985;34(3):127-129. DOI: 10.1080/07448481.1985. 9939622.

21. Sujon MK, Alam MK, Rahman SA. Prevalence of third molar agenesis: associated dental anomalies in non-syndromic 5923 patients. PLoS One 2016;11(8):e0162070. DOI: 10.1371/journal.pone.0162070.

22. Graber IW. Congenital absence of teeth: a review with emphasis on inheritance patterns. J Am Dent Assoc 1978;96(2):266-275. DOI: 10.14219/jada.archive.1978.0054.

23. Backman B, Wahlin YB. Variations in number and morphology of permanent teeth in 7 year old Swedish children. Int J Paediatr Dent 2001;11:11-17. 